\title{
Primary Research on Emergency Self-Rescue Furniture Design for Natural \\ Disasters
}

\author{
Ming CHEN \\ Forestry College, Sichuan Agricultural \\ University, Chengdu 611130, China \\ Key Laboratory of Wood Industry and Furniture \\ Engineering, Sichuan Agricultural University, \\ Chengdu 611130, China \\ chenming@sicau.edu.cn

\section{Li JIANG} \\ Forestry College, Sichuan Agricultural \\ University, Chengdu 611130, China
}

Key Laboratory of Wood Industry and Furniture

Engineering, Sichuan Agricultural University, Chengdu

611130, China

\begin{abstract}
In recent years, a large number of natural disasters happened in China, which caused heavy casualties, property losses and destruction of social order. Emergency self-rescue furniture design for natural disasters was taken as the research object in this paper. The definition and meanings of emergency self-rescue furniture were discussed, then the design principles of emergency self-rescue furniture were analyzed, validity of emergency self-rescue furniture design principles and methods for earthquake and flood were verified through demonstrations, finally.
\end{abstract}

Keywords: natural disasters, emergency self-rescue, furniture design

\author{
Da-Zhi LIU \\ Forestry College, Sichuan Agricultural \\ University, Chengdu 611130, China \\ Key Laboratory of Wood Industry and Furniture \\ Engineering, Sichuan Agricultural University, Chengdu \\ 611130, China \\ Jian-hua LYU* \\ Forestry College, Sichuan Agricultural \\ University, Chengdu 611130, China \\ Key Laboratory of Wood Industry and Furniture \\ Engineering, Sichuan Agricultural University, \\ Chengdu 611130, China \\ ljh@sicau.edu.cn \\ *Corresponding author
}

\section{Introduction}

China is one of a few countries which have severe natural disasters happened every year in the world. Almost all of natural disasters, such as droughts, floods, earthquakes, storms, typhoons, snowstorms, landslides, mudslides, pests, forest fires, and so on occur frequently in China. According to statistics, during 2013, a total of 388.187 million people were affected, 1,851 were killed and 433 were missing, 12.15 million people were evacuated; 875,000 houses were collapsed, 7.703 million houses were damaged to different extent; area-damaged of crops was $31,349,800 \mathrm{hm}^{2}$, of which $3,844,400$ $\mathrm{hm}^{2}$ had no harvests at all; direct economic loss was up to 580.84 billion RMB due to natural disasters in 2013. Overall, natural disasters in 
2013 are obviously most serious since 2000[1]. Natural disasters are manifestations of contradiction between man and nature in a sense, an inevitable event in the process of human development, it is also one of the most serious challenges that human beings should confront in the past, at the present, even in the future. So it's very important for human beings to take appropriate disaster prevention and mitigation measures. The domestic disaster prevention and mitigation system is imperfect for few related products. By summarizing the relevant theories, design principles and approaches were deduced and a series of emergency self-rescue furniture for natural disasters were designed as demonstration.

\section{Emergency Self-Rescue Furniture}

\subsection{Definition}

Furniture is a variety of essential instruments for human beings to maintain daily activities, production activities and social activities [2]. Furniture consists of four factors-material, structure, appearance and function, among them the function is the precursor and the driving force to promote the development of furniture; the structure is the backbone and the basis to implement functions. Emergency self-rescue furniture refers to a certain type of furniture that has the function of reducing threats and resisting damages by changing some particular structures or combining some special materials to achieve some forms that can help human to avoid or evade from calamity when natural disasters occur.

\subsection{Significance}

Generally, emergency self-rescue furniture is a type of multifunctional furniture. It seems ordinary furniture when there is no natural disaster, but when natural disaster occurs, it can also transform into a form to protect the safety of users and increase the survival rate by changing its structure. Emergency self-rescue function in furniture applications endows modern furniture new mission and vitality.

As people's living standards rising, people pay more attention to the safety of living environment, and their disaster prevention consciousness is also growing. The interior is the main place for people to work and rest, people spend more than half of the daily time indoors, so the interior becomes one of the most concentrated areas that cause casualties when natural disasters occur. Since people have closest contact with furniture indoors, so the emergency self-rescue furniture can directly reduce damage of natural disasters in some degree and increase people's survival rate to a large extent.

In addition, after Wenchuan earthquake in 2008, scholars did some research on degree of recognition about the quakeproof products which shows that people's earthquake mitigation awareness significantly increased, degree of recognition of the quakeproof products is rising continuously from single households in rural areas to multistoried and high-rise households in cities and towns after the earthquake[3]. Meanwhile, many multistoried and high-rise households put forward the desire to get the necessary help in the form of products. People are suffering from unpredictable natural disasters, especially people living in disaster-prone and hazard areas. People are fear of natural disasters and are not optimistic about the security, and such fears and insecurities will cause a lot of unnecessary mental loss [3]. Emergency self-rescue furniture indirectly gives people psychological comfort and increases their sense of security, while 
largely ensure people living and working in peace and contentment.

After accession to the WTO in the 21st century, Chinese furniture enterprises will be faced with the intense competition against foreign counterparts, in which will be increased from the original price competition to design competition. Improving the level of design and making own new products is the only way which must be passed for Chinese furniture industries [4].

China is prone to having natural disasters, causing heavy losses to individual and nation every year. Sensible earthquakes occur about 1000 times every year in Japan [5], which makes quakeproof products related with the Japanese people closely, and gives rise to the tremendous business opportunities simultaneously, hence, many companies produced various kinds of quakeproof products, and it has mainly formed an industry of the design and production for quakeproof and rescue products in Japan. Natural disaster is an opportunity for the development of the domestic furniture industry from the Japanese experience. What is more, it is also an important chance to open up new situation of China's furniture industry. We should seize the opportunity to develop a series of natural disaster emergency and self-rescue furniture, which should be designed with considering of the characters of natural disasters and the way hurting humans, combining with the modern human behaviors at the same time to meet the user's functional and psychological requirements, and finding the breakthrough point from the people's living needs and aesthetic thoughts. Through adding functions of the emergency self-rescue to guide the forward-thinking and forward-looking development of our country furniture design and to improve the international competitiveness [6].

\section{Design Principles and Demonstration of Emergency Self-rescue Furniture}

Natural disasters are generally difficult to accurately forecast for the uncertainty. When natural disasters happen, emergency self-rescue furniture can be changed to unique form to provide security for the people around it. Because the disaster are fast and strong destructive, designers should pay more attention on the design of the structure, material selection, the way in which the furniture can transfer from ordinary form into emergency self-rescue form quickly during the design process.

In addition, although the frequency of domestic natural disasters is relative high, it doesn't happen uninterruptedly. Thus the design should use existing problems combining with the structure and the furniture of different emergency self-rescue furniture space expect its emergency self-rescue and traditional function to achieve multifunctional furniture which can solve problems and meet the daily demand of modern people.

\subsection{Design Principles}

Structural design is an important part of product design [7], because structure refers to the formation and combination of the each element of product, and it is the basis of function implementation which directly affects the furniture. Natural disasters with strong destructive power have a great influence on the basic function of furniture. Designers should put the functions together so that the furniture can not only overcome the external force disturbance, but also to protect people with consideration in natural disasters, and build reasonable supporting system by applying the laws of mechanics to make sure the structure stabile. 
Furniture material is the material base of furniture function realization and the carrier of furniture art design. The properties and types of material not only affect furniture appearance shape, but also promote or restrict effect on the realization of the function of furniture. Emergency self-rescue furniture was used as ordinary furniture in daily life while used to provide the function of protection or facilitate people to escape in disaster. But function and form of the furniture should be uniform, which means, this kind of furniture is varied in the form, and it can achieve the required functionality through the change of the form. But the disaster which usually has direct harm to people inside the building generally can produce enormous damage in a short period of time. So when designers are choosing materials, on one hand, it should meet demands of the emergency self-rescue style of simple and fast transformation, on the other hand, it should have the characteristics of strong destruction-resisting power simultaneity and so on.

The small apartment has become the most valuable purchase choice for modern young people due to the rising prices of real estate in recent years. Because of limited space people lives, people should make the furniture multifunctional and practical values of furniture improved, which can meet design principles from consumers' demands and social development.

\subsection{Design for Demonstration}

Generally, people live indoor with all kinds of doors, when natural disasters happened, doors usually can't be opened because of extrusion deformation easily caused by vibration, which creates obstacles in the situation that a few seconds delay may cause serious consequences and cause harm to people. In order to solve this problem, the emergency exit door is designed as shown in figue1. It overcomes the shortcomings that current doors have during the earthquakes and other issues.

Figure 1 show that on the left side of the door is the shape of furniture at the emergency self-rescue form. Lower door is opened, hidden inner door plank within the lower door plank slides out, and the inner door plank will be make to self-locking under the action of the elastic limit column. The triangle with stability is used to make the bottom of the door to form stable triangular space. In addition, the stability of the triangular space can provide people with a brief shelter to protect people from being injured by falling objects.
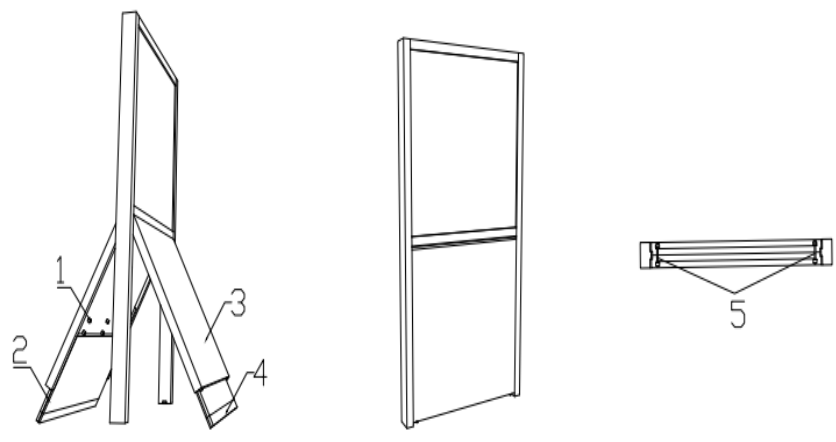

Fig. 1 Emergency exit door

1. Elastic limit column; 2.Inner door; 3.Lower door; 4.Shock pad; 5.Hardware bolts

Emergency exit door mentioned above is mostly used for earthquakes. In order to ensure the normal use of escape door in security, its lower door plank is usually closed. It is convenient for people to transfer the door in the middle condition to the left condition through two types of hardware bolts at the bottom of the lower door with sufficient distance from the bottom. In addition, in order to make the lower door automatically form triangular space with strong stability when open, the springs be set up at the contact point of the elastic limit column and the lower door, which can make the spring 
physical properties and the limit column work together to let the door plank self-locking, which form the stable triangular space as shown left condition in figure 1. According to the characteristics of the earthquake, emergency self-rescue furniture used in the earthquake should have good anti-seismic, compressive properties. In the design of the exit door, the shock pad be installed at the bottom of the inner door plank, which can protect the inner door plank while play function of shock absorption.

Combined with the characteristics of flood water logging disaster, a kind of recreational sofa was designed as shown in figure 2. It's the sofa's working form in security, when the flood water logging disasters occur, it can be transformed into the form of middle condition in figure 2. The key to achieve the transformation between the two forms is telescopic connecting rod and flexible connector between the base of sofa and the curved back. The sofa can be converted from the form in the left to the middle in figure 2 through both connectors mentioned above and added external force, through lever principle. In addition, with the same method, the curved back of sofa can also be pulled up, which can be used for shockproof as right position shown in figure 2 .
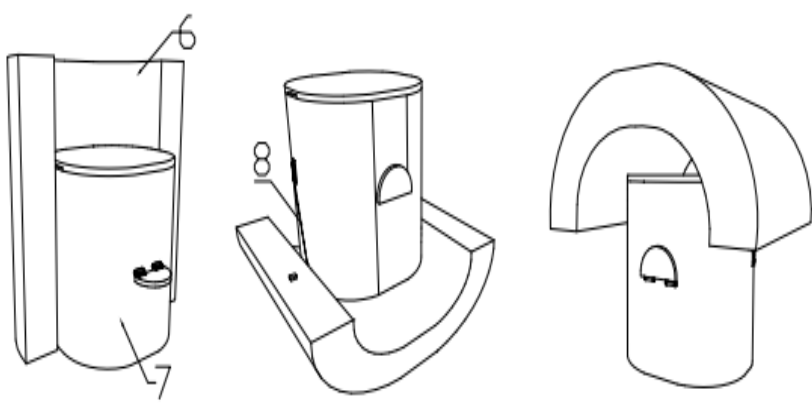

Fig. 2 Recreational sofa

6. Curved back; 7. Base; 8.Flexible connectors

According to self-rescue experience in flood disaster, the inflatable balloon is set in the outer wall of the curved back. Opening inflatable balloon can increase buoyancy of the sofa in the water, making sofa and people shelter in the bottom cavity float on the water, which can increase the survival rate. In addition, when it is used as anti-shock furniture, the inflatable balloon at the upper part of the base can play a cushioning effect on dropping things.

Emergency self-rescue furniture should be designed on the basis of the using space, consumers and special configuration should be placed in order to improve the using values. The instruction for emergency self-rescue steel frame bed in dormitory room was designed as follows.

It is reported that the reasons many students were injured in earthquakes are jumping from the bed directly or falling off from the ladder with panic instead of collapsing of building or hitting by something drop off in the dormitory. As a result, an emergency self-rescue steel frame bed was designed which can help students get down fast and safely. Compared with general dormitory steel frame bed, it has a unique guardrail which can become escalator to solve the problem that students on the bunk get down unsafely and slowly. At the same time, it can become a desk which can solve problems such as the little space, inconvenient writing in daily life.

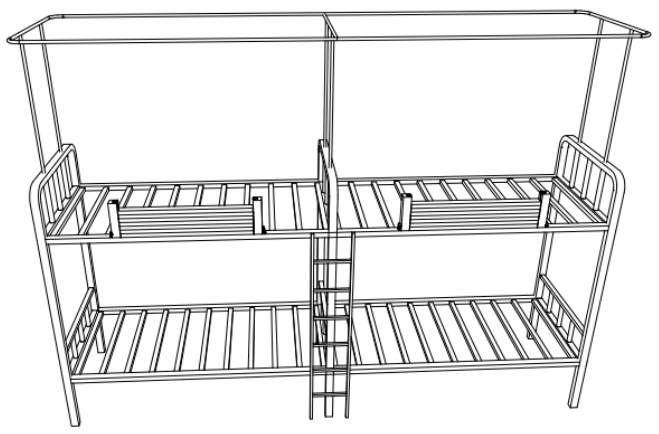



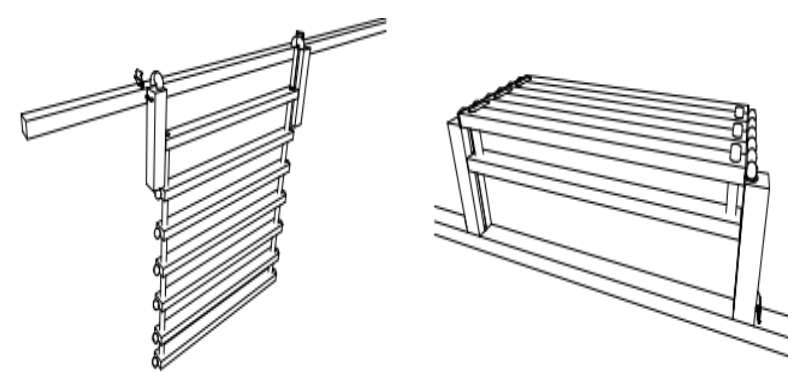

Fig. 3 Emergency self-rescue steel frame bed

\subsection{Summary of Design}

Emergency self-rescue furniture is aimed at providing an indoor shelters in disasters with setting in the safest place in home to protect people with adding special furniture widget, such as hardware[8], intelligent airbag[9], rubber[10,11], etc. Combined with the aesthetic psychology of the user and function requirements while not affecting the appearance, these widgets with advantage of their unique properties used in furniture to work together can play an important role by making furniture quickly transfer to the position that could protect or support self-rescue function. Secondly, damage strength of natural disasters usually is strong, so the stability and completeness of furniture in disasters are also very important. Generally, natural disasters can cause a variety of secondary disasters which let people off guard, panic and miss the best time to escape, therefore, during design process priority should be given to the furniture that has two or more natural disaster emergency self-rescue solutions in order to provide more options for people.

\section{Conclusion}

Since reform and opening up policy started in China, disaster and emergency management has made considerable progress, but there are still problems like weak awareness of disaster prevention and mitigation, ineffective mitigation and emergency mechanism, backward technology and equipment, lack of investment and so on. Since 2008, China has experienced a number of severe natural disasters, such as Wenchuan Earthquake, Yushu Earthquake, Zhouqu Mudslides, Beijing 7.21 Floods, Yiliang Earthquake, Ludian Earthquake and other severe calamity occurred frequently, caused heavy casualties and property losses over and over again which brings tremendous pains to the Chinese people. Through careful thought, summary of the profound lessons and emergency self-rescue as a prerequisite in a disaster, a series of emergency self-rescue furniture were designed in order to protect its users or people around to some degree, thus reducing the number of casualties in disasters.

At present, it hasn't formed a relatively mature and stable research and industrial systems of disaster prevention and mitigation of furniture. It's still challenges for furniture designers to design emergency self-rescue furniture due to lack of experience, technology and equipment, but with the development of science and more expectation for emergency self-rescue furniture, designers are able to overcome the difficulties, and bring beautiful, portable, safe, practical, durable, usable and universal emergency self-rescue furniture for mankind.

\section{Acknowledgements}

A Project Supported by Scientific Research Fund of Sichuan Provincial Education Department (Grant No. 13SB0202 \&13ZB0281). A Project Supported by Sichuan Provincial Fund of Talent Training Quality and Teaching Reform in Higher Education (Grant No. 2014-156-184). A Project Supported by Sichuan Provincial Key Research Base of Philosophy and Social Science-Yi Culture Research Center (Grant No. YZWH1433). 


\section{References}

[1] Basic information of national natural disasters in 2013 [EB/OL].http://www.chinajyzb.com.cn/han gyedongtai/1160.html, 2014-01-04.

[2] Zhihui Wu. Wood Furniture Manufacturing Technology [M]. Beijing: China Forestry Publishing House,2012.

[3] Yingjie Jia.Household defensive products design and research to earthquake [D]. Chengdu: Southwest Jiaotong University., 2009, 8 .

[4] Wenli Peng. The research on related between furniture material and furniture design [D].Changsha: Central South University of Forestry and Technology, 2005.

[5] Xu Zhang. Through the earthquake observation Japanese unique temperament [J]. Xiaokang, 2011(4): 61-62.
[6] Shan Luo, HuiYuan Guan. The design and discussion cabinet furniture to anti-seismic and disaster reduction $[\mathrm{J}]$. Shanxi Architecture, 2012, 36(38):26-27.

[7] Delin Sun, Debin Sun. Discussion on the teaching methods of furniture structure design [J]. Furniture And Interior Decoration, 2010,(6):106-107.

[8] Jianwei Huang. The function of the hardware and configuration scheme [J]. Doors And Windows, 2010(05):37-39.

[9] Shanhong Li. The development of smart airbag system [D]. Jilin University, 2007.

[10] Guangxian Zhao. The application of rubber in the earthquake resistance [J]. China Rubber, 2008,24(20):31-34.

[11] Haiyan Liu, Guofu Liang. Discussion on the technical characteristics of home fires escape equipments [J]. Fire Science And Technology, 2011, 30(5): 425-428. 